\title{
Peritumoral cysts associated with pituitary macroadenoma
}

\author{
Ryan F. Herde, MD, MS, ${ }^{1}$ Nguyen Hoang, MD, ${ }^{2}$ Diem Kieu Tran, MD, ${ }^{2}$ Genevieve Couldwell, ${ }^{2}$ \\ William T. Couldwell, MD, PhD, ${ }^{2}$ and Anne G. Osborn, MD'1
}

Departments of ${ }^{1}$ Radiology and ${ }^{2}$ Neurosurgery, Clinical Neurosciences Center, University of Utah, Salt Lake City, Utah

\begin{abstract}
OBJECT Peritumoral cysts are benign nonneoplastic cysts that are found adjacent to extraaxial brain tumors such as meningiomas, schwannomas, craniopharyngiomas, and esthesioneuroblastomas. Peritumoral cysts associated with pituitary macroadenomas have not been previously described in the literature. The authors report 6 cases of giant macroadenoma-associated peritumoral cysts and delineate their imaging spectrum.
\end{abstract}

METHODS The authors retrospectively reviewed the records of 179 patients diagnosed with pituitary macroadenomas who underwent tumor resection at their institution and had preoperative MRI scans available for review. The patients were evaluated for the presence of associated peritumoral cysts. Clinical presentation, histopathology, follow-up time, tumor and peritumoral cyst dimensions were recorded. Signal intensity on T1-weighted, T2-weighted, diffusion-weighted, and FLAIR sequences, as well as pre- and postcontrast appearance, were determined.

RESULTS Six patients (3.4\%) with associated peritumoral cysts were identified in our cohort of 179 patients with pituitary macroadenoma. Twelve patients in the cohort had giant macroadenomas ( $\geq 4.0 \mathrm{~cm})$, and $50 \%$ of these tumors had associated peritumoral cysts with significant extrasellar extension of the macroadenoma. Only tumors with craniocaudal, transverse, and anteroposterior diameters of $3.6 \times 3.4 \times 4.2 \mathrm{~cm}$ to $7.0 \times 7.4 \times 6.8 \mathrm{~cm}$ (mean $5.3 \times 5.1 \times 5.6 \mathrm{~cm})$, respectively, had associated peritumoral cysts. The growth pattern in all tumors was suprasellar, with predominant anterior and lateral extension.

Cysts showed T1-weighted, T2-weighted, and FLAIR hyperintensity in 67\%,67\%, and $60 \%$ of patients, respectively. There was no contrast enhancement of the cyst wall or fluid contents in any patient. Postoperatively, cysts had completely resolved (4 of 5) or significantly decreased in size (1 of 5). One patient was lost to follow-up.

CONCLUSIONS Macroadenoma-associated peritumoral cysts are rare, benign, and likely nonneoplastic fluid collections that do not represent neoplasm. These cysts display a predictable pattern of hyperintensity on T1-weighted, T2weighted, and FLAIR sequences and do not enhance. They most likely represent proteinaceous CSF in a sulcus or cistern that becomes trapped (encysted) by anterolateral extension of unusually large macroadenomas. Peritumoral cysts may facilitate resection of the associated macroadenoma by providing a cleavage plane.

http://thejns.org/doi/abs/10.3171/2014.12.JNS141031

KEY WORDS peritumoral cyst; intracranial cyst; macroadenoma; tumor-associated cyst; nonneoplastic cyst; pituitary surgery

$\mathrm{P}$ ERITUMORAL cysts are benign nonneoplastic cysts that have been reported in association with extraaxial brain tumors including meningioma, schwannoma, craniopharyngioma, and esthesioneuroblastoma. ${ }^{1,16} \mathrm{Pe}-$ ritumoral cysts occurring with pituitary macroadenomas are occasionally observed on imaging, at surgery or on autopsy (Fig. 1), but have not been previously described in the literature. We report 6 cases of juxtatumoral cysts associated with giant macroadenomas and delineate their imaging spectrum.

\section{Methods}

In this institutional review board-approved retrospective study, we reviewed the records of patients who underwent resection for pituitary macroadenoma in our institution from January 2001 through August 2013 for whom pre- and postoperative imaging was available for review. One hundred seventy-nine patients diagnosed with pituitary macroadenoma (defined as a pituitary adenoma $\geq 1$ $\mathrm{cm}$ in maximum diameter) were identified. Preoperative

ABBREVIATIONS $A P=$ anteroposterior; $C C=$ craniocaudal; $D W I=$ diffusion-weighted imaging; $T=$ transverse.

SUBMITTED June 5, 2014. ACCEPTED December 18, 2014.

INCLUDE WHEN CITING Published online July 3, 2015; DOI: 10.3171/2014.12.JNS141031.

DISCLOSURE The authors report no conflict of interest concerning the materials or methods used in this study or the findings specified in this paper. 


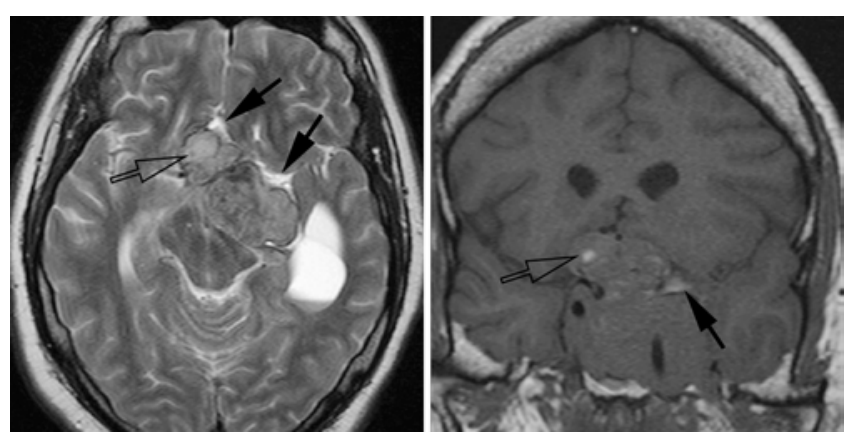

FIG. 1. Case 2. Preoperative imaging demonstrating both intratumoral and peritumoral cysts. Left: Axial precontrast T2-weighted MR image showing a large lobulated macroadenoma with presence of a common, intratumoral cyst (hollow arrow) and rare, peritumoral cysts resulting from obstruction of the left sylvian fissure and right olfactory sulcus (arrows). Also present is an obstructed temporal horn of the left lateral ventricle. Right: Coronal T1-weighted MR image also showing an intratumoral cyst (hollow arrow) and peritumoral cyst located in left sylvian fissure (arrow).

imaging was initially reviewed for size in each case to confirm a diagnosis of pituitary macroadenoma. Age at initial diagnosis, sex, histopathology, and clinical presentation were tabulated.

Preoperative MRI scans were reviewed by a neuroradiologist holding certification of added qualifications for the presence or absence of associated peritumoral cyst(s). Imaging findings were analyzed for tumor size measured in 3 dimensions (craniocaudal [CC], transverse [T], and anteroposterior $[\mathrm{AP}]$ ), presence and direction of tumor extrasellar extension, tumor shape, presence of intratumoral hemorrhage, and restriction on diffusion-weighted imaging (DWI). Tumor volume was approximated by a modified ellipsoid volume formula $(\mathrm{CC} \times \mathrm{T} \times \mathrm{AP} / 2)$. Peritumoral cysts were examined for signal hyperintensity on T1- and T2-weighted MR images in addition to FLAIR sequences by comparing the measured point value of cyst fluid to CSF within the ventricles. Cyst margins and contents were also evaluated for the presence of enhancement on postcontrast T1-weighted MRI scans. Where available, postoperative MRI scans were also reviewed for resolution of cysts and other postoperative changes. The length of follow-up was determined from clinical records and was defined as time from resection to when the last documented MRI study was performed.

\section{Results}

\section{Clinical and Histopathological Findings}

Twelve patients were identified with giant macroadenomas ( $\geq 4.0 \mathrm{~cm}$ in maximum diameter); 6 patients $(3.4 \%$ ) had macroadenoma-associated peritumoral cysts within our cohort of 179 patients with pituitary macroadenoma. There were 3 female and 3 male patients. Mean age at diagnosis was 39 years (range 25-57 years). All patients were symptomatic at presentation. Four patients presented with symptoms of visual loss, although none had classic bitemporal hemianopsia. Cognitive decline was present in 3 patients, with incontinence secondary to hydrocephalus presenting concomitantly in the single patient with symp- tomatic hydrocephalus. Two patients presented with headache as a primary symptom. One patient presented with endocrine abnormalities, and 1 patient presented with a CSF leak (Table 1).

Three of the 6 patients had null cell adenomas on histopathological analysis. One patient had a mixed adenoma of the lactotrophic/somatotrophic (prolactinoma/growth hormone-secreting) subtype, 1 had a lactotrophic adenoma, and 1 had a mixed gangliocytoma/somatotrophic adenoma, a rare 2-cell type of tumor. Two patients had transsphenoidal resections, whereas 4 patients underwent both transsphenoidal and transcranial procedures. The mean follow-up time was 4.1 years (range $0.5-8.9$ years), with 1 patient lost to follow-up (Table 1).

\section{Imaging Findings}

All 6 macroadenomas were multilobular in shape and exhibited suprasellar extension; 4 (67\%), 5 (83\%), and 3 $(50 \%)$ of the macroadenomas also displayed inferior, anterior, and posterior growth patterns, respectively. Mean $\mathrm{CC}$, T, and AP tumor dimensions were $5.3 \mathrm{~cm}$ (range $3.6-7.0 \mathrm{~cm}$ ), $5.1 \mathrm{~cm}$ (range 3.4-7.4 cm), and $5.6 \mathrm{~cm}$ (range $4.2-6.8 \mathrm{~cm}$ ), respectively. Mean tumor volume was 77.3 $\mathrm{cm}^{3}$ (range $41.6-138.6 \mathrm{~cm}^{3}$ ). Associated peritumoral cysts had a mean diameter of $2.9 \mathrm{~cm}$ (range 0.6-5.8 cm). On imaging, all 6 macroadenomas obstructed or trapped adjacent sulci and fissures, leading to peritumoral cyst formation. Four patients had cysts involving the sylvian fissure, 3 involving the olfactory sulcus, and 1 each involving the suprasellar cistern and interhemispheric fissure. Three pa-

TABLE 1. Demographic and clinical characteristics of patients with pituitary macroadenoma

\begin{tabular}{lc}
\hline \multicolumn{1}{c}{ Characteristic } & \multicolumn{1}{c}{ Value* } \\
\hline Total group & $6(100 \%)$ \\
\hline Sex & $3(50 \%)$ \\
\hline $\mathrm{M}$ & $3(50 \%)$ \\
\hline $\mathrm{F}$ & $39(25-57)$ \\
\hline Mean age at diagnosis in yrs (range) & \\
\hline Clinical presentation† & $4(67 \%)$ \\
\hline Visual loss & $3(50 \%)$ \\
\hline Cognitive decline & $2(33 \%)$ \\
\hline Headache & $1(17 \%)$ \\
\hline Incontinence (hydrocephalus) & $1(17 \%)$ \\
\hline Endocrine abnormalities & $1(17 \%)$ \\
\hline CSF leak & $3(50 \%)$ \\
\hline Pituitary adenoma types & $1(17 \%)$ \\
\hline Null cell & $1(17 \%)$ \\
\hline Lactotrophic & $1(17 \%)$ \\
\hline Mixed (somato-/lactotrophic) & \\
\hline Mixed gangliocytoma/somatotrophic adenoma & $2(33 \%)$ \\
\hline Resection & $4(67 \%)$ \\
\hline Transsphenoidal & $4.1(0.5-8.9)$ \\
\hline Transsphenoidal and transcranial & \\
\hline Follow-up time in yrs (range) & \\
\hline
\end{tabular}

* Number of patients (\%) unless otherwise indicated.

$\dagger$ Several patients presented with more than 1 chief complaint. 
tients had solitary peritumoral cysts while the other 3 had 2 or more cysts associated with their tumor (Table 2).

In $4(67 \%)$ of the 6 patients, cyst fluid was hyperintense relative to CSF on T1- and T2-weighted MRI sequences (Fig. 2). One patient with pituitary apoplexy had hemorrhage into the peritumoral cyst. Five of 6 patients had available FLAIR sequence data; $3(60 \%)$ of 5 patients had hyperintense cystic lesions. In 2 patients, cyst fluid was isointense with CSF on all sequences. None of the peritumoral cyst walls or fluid enhanced with contrast. DWI sequences were available for review in 3 patients, and 1 patient demonstrated restricted diffusion (Table 3 ).

Postoperative MRI scans were available in 5 of 6 patients. The peritumoral cysts had completely resolved in 4 patients $(80 \%)$ and had significantly decreased in size in 1 patient $(20 \%)$. There were no recurrences or new hyperintensities in any patient (Table 3).

\section{Discussion}

There are 2 types of cysts associated with extraaxial CNS neoplasms (e.g., meningioma, schwannoma, craniopharyngioma, and esthesioneuroblastoma): peritumoral and intratumoral. Peritumoral cysts (i.e., tumor-associated cysts) are nonneoplastic cysts that develop at tumor margins. Intratumoral cysts develop within the tumor itself and are usually due to microcystic degeneration, ischemic necrosis, or hemorrhage within the tumor. ${ }^{1,5,16,22}$ The pathogenesis of peritumoral cysts is thought to be quite different. Proposed mechanisms include reactive gliosis, peritumoral edema, or trapping of CSF within the cleft between the expanding tumor and adjacent brain. ${ }^{2,9,12,15,20,21}$ The latter mechanism is the most likely etiology of the cysts in our study.

TABLE 2. Macroadenoma and peritumoral cyst characteristics

\begin{tabular}{lc}
\hline \multicolumn{1}{c}{ Characteristic } & Value $^{*}$ \\
\hline Tumor shape & $6(100 \%)$ \\
\hline Multilobular & \\
\hline Tumor growth pattern & $6(100 \%)$ \\
\hline Superior & $4(67 \%)$ \\
\hline Inferior & $5(83 \%)$ \\
\hline Anterior & $3(50 \%)$ \\
\hline Posterior & $5.3(3.6-7.0)$ \\
\hline Tumor dimensions (range) & $5.1(3.4-7.4)$ \\
\hline CC in cm & $5.6(4.2-6.8)$ \\
\hline T in cm & $77.3(41.6-138.6)$ \\
\hline AP in cm & $2.9(0.6-5.8)$ \\
\hline Volume in cm ${ }^{3}$ & \\
\hline Associated cyst diameter in cm (range) & $4(67 \%)$ \\
\hline Cyst locations $\dagger$ & $3(50 \%)$ \\
\hline Sylvian fissure & $1(17 \%)$ \\
\hline Olfactory sulcus & $1(17 \%)$ \\
\hline Suprasellar cistern &
\end{tabular}

* Number of patients (\%) unless otherwise indicated.

$\dagger$ Three of 6 patients had 2 or more peritumoral cysts.
Elevated protein concentrations (relative to CSF) have been found in the fluid of peritumoral cysts in several studies. ${ }^{6,9-11}$ We did not evaluate the biochemical composition of peritumoral cystic fluid associated with pituitary macroadenoma and the operating surgeon did not notice a proteinaceous or xanthochromic fluid during the course of resection. All macroadenomas were resected transsphenoidally, either as primary resection or in the initial
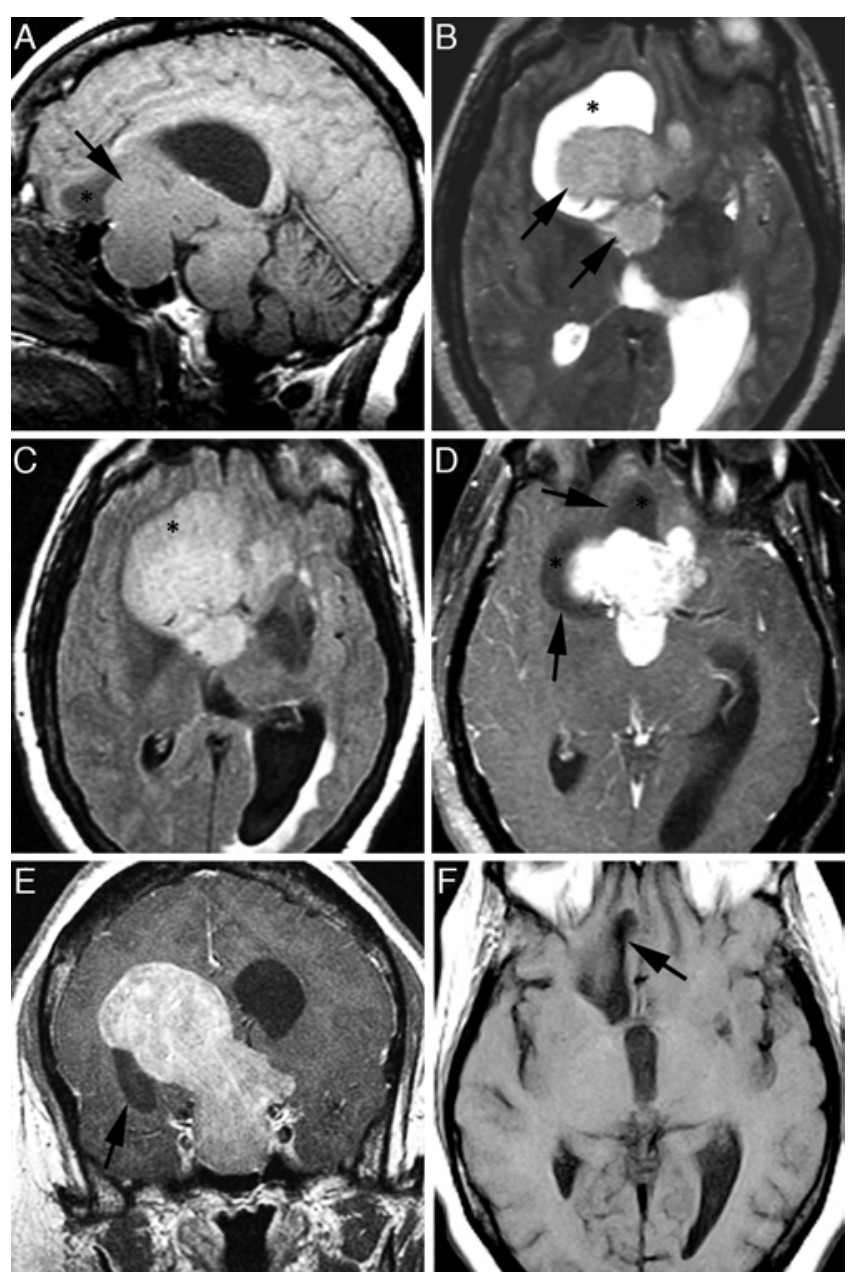

FIG. 2. Case 4. Preoperative and postoperative imaging. A: Preoperative sagittal precontrast T1-weighted MR image showing a large lobulated macroadenoma with significant suprasellar extension (arrow). The left lateral ventricle is obstructed and enlarged. A peritumoral cyst can be seen just anterior to the tumor. Cyst fluid identified by the asterisk $\left(^{*}\right)$ is moderately hyperintense to CSF in the trapped ventricle. B: Preoperative axial T2-weighted MR image showing the lobulated tumor (arrows) and a large unilocular peritumoral cyst almost completely surrounding the macroadenoma. The cyst fluid measured moderately hyperintense relative to CSF. C: Preoperative axial FLAIR image showing that the cyst fluid (indicated by asterisk) is significantly hyperintense relative to CSF and does not suppress. D: Preoperative axial postcontrast, fat-saturated T1-weighted MR image showing that the lobulated macroadenoma enhances intensely. The cyst wall (arrows) and cyst fluid (indicated by asterisk) do not enhance. E: Preoperative coronal postcontrast T1-weighted MR image showing the superolateral extension of the macroadenoma. The juxtatumoral cyst wall (arrow) does not enhance. F: Axial precontrast T1-weighted MR image showing postoperative collapse of peritumoral cyst (arrow) that is communicating with the right lateral ventricle. 
TABLE 3. Preoperative peritumoral cyst MRI characteristics and postoperative outcome

\begin{tabular}{|c|c|c|c|c|c|c|c|c|}
\hline \multirow{2}{*}{$\begin{array}{l}\text { Case } \\
\text { No. }\end{array}$} & \multicolumn{3}{|c|}{ Hyperintensity Pattern } & \multirow{2}{*}{$\begin{array}{c}\text { Contrast } \\
\text { Enhancement }\end{array}$} & \multirow[b]{2}{*}{ DWI Restriction } & \multirow{2}{*}{$\begin{array}{c}\text { Prominent } \\
\text { Perivascular Spaces }\end{array}$} & \multirow[b]{2}{*}{ Hemorrhage } & \multirow{2}{*}{$\begin{array}{l}\text { Postop Cyst } \\
\text { Resolution }\end{array}$} \\
\hline & $\mathrm{T} 1$ & $\mathrm{~T} 2$ & FLAIR & & & & & \\
\hline 1 & + & $t^{*}$ & $\mathrm{NA} \dagger$ & - & NA $†$ & - & - & Complete \\
\hline 2 & + & + & + & - & - & - & + & Partial \\
\hline 3 & - & - & - & - & $\mathrm{NA} \dagger$ & - & - & Complete \\
\hline 4 & + & + & + & - & $\mathrm{NA} \dagger$ & - & - & Complete \\
\hline 5 & + & + & + & - & - & - & - & NA \\
\hline 6 & - & - & - & - & + & - & - & Complete \\
\hline Total & $4(67 \%)$ & $4(67 \%)$ & $3(60 \%)$ & 0 & $1(33 \%)$ & 0 & $1(17 \%)$ & \\
\hline
\end{tabular}

approach, so observation of the surrounding peritumoral cysts and the response to surgical decompression was not possible. The walls of the cysts were not specifically sampled at the time of surgery; drainage of cysts occurred at the time of the resection as verified on postoperative imaging. The preoperative MRI findings in our cases, however, are consistent with elevated protein concentrations within most of the peritumoral cysts, which were hyperintense on T1-weighted and FLAIR imaging sequences in the majority of our patients., ${ }^{713}$ The high prevalence of hyperintensity on T2-weighted images is also consistent with cystic lesions and peritumoral edema ${ }^{4,9}$ We also observed in the 2 cases with isointense cystic fluid that the CSF flow within these spaces was not completely obstructed, and they continued to communicate to some extent with the ventricles and subarachnoid space. None of our 6 cases showed enhancement on postcontrast MRI scans, which is consistent with previously reported findings and indicates that neither blood-brain barrier disruption nor the tumor itself is the source of the peritumoral cysts. ${ }^{8,9}$ Thus, it is likely that as a juxtatumoral cleft becomes completely trapped, it begins to become more proteinaceous relative to CSF.
In previous studies, entrapment or loculation of CSF was criticized as an improbable mechanism of peritumoral cyst formation in extraaxial tumors, ${ }^{3,9,14}$ although these studies did not evaluate cysts associated with pituitary macroadenoma. Each tumor in our study demonstrated an anatomical relationship to the surrounding fissures and sulci, indicating that the expanding tumor likely traps CSF in the adjacent cleft. We observed that peritumoral cysts were only associated with macroadenomas that grew to a diameter of at least $4.2 \mathrm{~cm}$ in the AP direction. The only macroadenoma less than $4.0 \mathrm{~cm}$ in either the $\mathrm{CC}$ or T diameters also had reached the maximal AP diameter, 6.8 $\mathrm{cm}$, achieved by any tumor in our study. During our investigation, we identified only 12 patients $(7 \%)$ with giant macroadenomas (defined as a tumor $\geq 4.0 \mathrm{~cm}$ ) that were $\geq$ $4.2 \mathrm{~cm}$ in any dimension, the minimum diameter we observed in patients with cysts (data not shown). Six of these patients did not develop cysts, which was likely because of the primarily suprasellar growth pattern with T or AP diameters less than $4.2 \mathrm{~cm}$ (Fig. 3). The 6 cases included in our study also had exclusively multilobular macroadenoma shapes, whereas the other 6 patients had either rounded or "snowman"-shaped tumors. The size and growth pat-
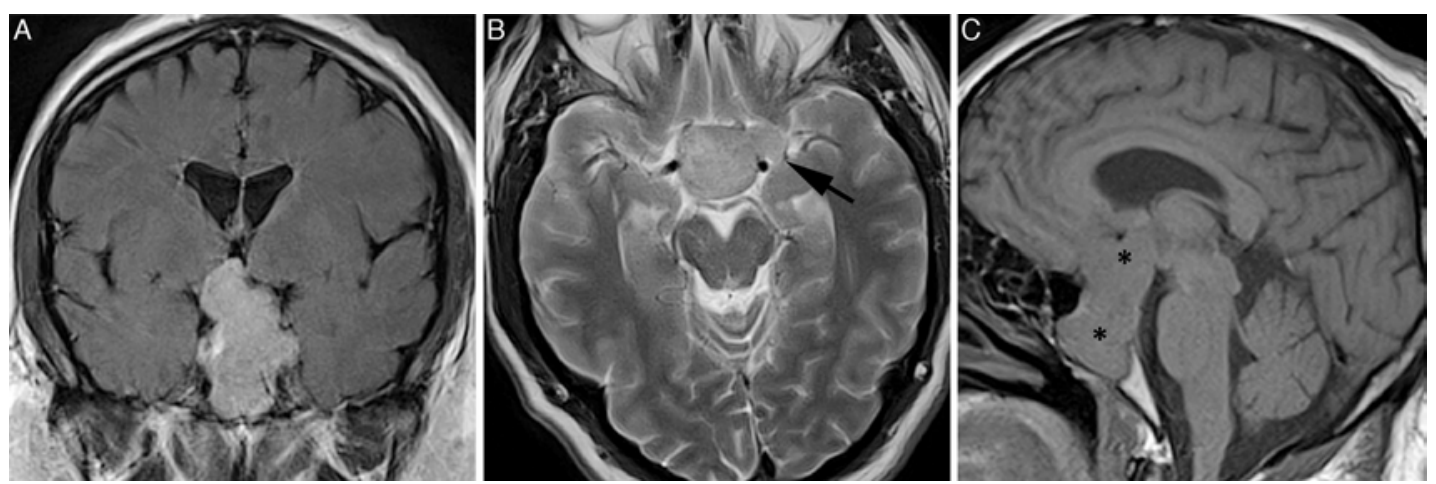

FIG. 3. Images obtained in 1 of 6 patients with giant macroadenoma (dimensions of $5.1 \times 2.8 \times 2.5 \mathrm{~cm}$ in the CC, T, and AP diameters, respectively) who did not develop associated peritumoral cysts. A: Coronal T1-weighted precontrast MR image showing predominantly CC growth pattern without associated peritumoral cyst. B: Axial T2-weighted MR image showing a lobulated macroadenoma with T extension toward left sylvian fissure but without obstruction (arrow). C: Sagittal T1-weighted MR image also demonstrating predominant suprasellar growth pattern of macroadenoma (asterisks) with minimal AP growth. 
tern correlation in our study supports a primary etiology of CSF obstruction in peritumoral cysts associated with pituitary macroadenoma.

It is generally believed that resection of the associated neoplasm with evacuation of cyst fluid will decompress and resolve the peritumoral cyst; ${ }^{9}$ however, some authors have shown persistence of the cyst despite this method and have postulated that there may be neoplastic meningothelial cells within the cyst wall. ${ }^{8,19}$ Others have reported that cyst walls consist of glial cell proliferation as confirmed by the presence of glial fibrillary acidic protein. ${ }^{17,18}$ In our study, we did not observe any evidence of a cystic capsule, and with no recurrences, it is unlikely that glia play a role in peritumoral cyst formation associated with pituitary macroadenoma. Thus, the cyst itself does not need to be resected or drained if the associated tumor is sufficiently resected to relieve the obstruction. The cyst may actually aid in tumor resection by providing an enhanced cleavage plane to spare normal brain.

\section{Conclusions}

Peritumoral cysts associated with pituitary macroadenoma are uncommon and previously undescribed in the literature. These cysts are likely nonneoplastic, occur outside of the tumor margins, and should not be mistaken for neoplasm. Here, we report 6 cases that were associated with large macroadenomas that demonstrated extensive anterolateral growth resulting in obstruction of CSF in adjacent brain fissures or sulci. These cysts do not appear to recur or increase in size after surgical decompression and resection of the associated macroadenoma. Peritumoral cysts may aid in resection by functioning as a cleavage plane while resection of the cysts themselves is likely unnecessary.

\section{Acknowledgment}

We thank Kristin Kraus for all of her help in preparing the manuscript for publication.

\section{References}

1. Baggenstos MA, Butman JA, Oldfield EH, Lonser RR: Role of edema in peritumoral cyst formation. Neurosurg Focus 22(5):E9, 2007

2. Buetow MP, Buetow PC, Smirniotopoulos JG: Typical, atypical, and misleading features in meningioma. Radiographics 11:1087-1106, 1991

3. Dell S, Ganti SR, Steinberger A, McMurtry J III: Cystic meningiomas: a clinicoradiological study. J Neurosurg 57:8-13, 1982

4. Dunn IF, Bi WL, Erkmen K, Kadri PA, Hasan D, Tang CT, et al: Medial acoustic neuromas: clinical and surgical implications. J Neurosurg 120:1095-1104, 2014

5. Fortuna A, Ferrante L, Acqui M, Guglielmi G, Mastronardi L: Cystic meningiomas. Acta Neurochir (Wien) 90:23-30, 1988

6. Gläsker S, Vortmeyer AO, Lonser RR, Lubensky IA, Okamoto $\mathrm{H}, \mathrm{Xia} \mathrm{JB}$, et al: Proteomic analysis of hemangioblastoma cyst fluid. Cancer Biol Ther 5:549-553, 2006
7. Gomez-Brouchet A, Delisle MB, Cognard C, Bonafe A, Charlet JP, Deguine O, et al: Vestibular schwannomas: correlations between magnetic resonance imaging and histopathologic appearance. Otol Neurotol 22:79-86, 2001

8. Liu M, Liu Y, Li X, Zhu S, Wu C: Cystic meninigioma. J Clin Neurosci 14:856-859, 2007

9. Lohle PN, Wurzer HA, Seelen PJ, Kingma LM, Go KG: Cystic lesions accompanying extra-axial tumours. Neuroradiology 41:13-17, 1999

10. Lohle PN, Wurzer HA, Seelen PJ, Kingma LM, Go KG: The pathogenesis of cysts accompanying intra-axial primary and metastatic tumors of the central nervous system. J Neurooncol 40:277-285, 1998

11. Lonser RR, Vortmeyer AO, Butman JA, Glasker S, Finn MA, Ammerman JM, et al: Edema is a precursor to central nervous system peritumoral cyst formation. Ann Neurol 58:392-399, 2005

12. Mittal A, Layton KF, Finn SS, Snipes GJ, Opatowsky MJ: Cystic meningioma: unusual imaging appearance of a common intracranial tumor. Proc (Bayl Univ Med Cent) 23:429-431, 2010

13. Mulkens TH, Parizel PM, Martin JJ, Degryse HR, Van de Heyning PH, Forton GE, et al: Acoustic schwannoma: MR findings in 84 tumors. AJR Am J Roentgenol 160:395-398, 1993

14. Nauta HJ, Tucker WS, Horsey WJ, Bilbao JM, Gonsalves C: Xanthochromic cysts associated with meningioma. J Neurol Neurosurg Psychiatry 42:529-535, 1979

15. Odake G: Cystic meningioma: report of three patients. Neurosurgery 30:935-940, 1992

16. Osborn AG, Preece MT: Intracranial cysts: radiologicpathologic correlation and imaging approach. Radiology 239:650-664, 2006

17. Pinna G, Beltramello A, Buffatti P, Signorini G, Colombari R, Bricolo A, et al: Cystic meningiomas-an update. Surg Neurol 26:441-452, 1986

18. Rengachary S, Batnitzky S, Kepes JJ, Morantz RA, O'Boynick P, Watanabe I: Cystic lesions associated with intracranial meningiomas. Neurosurgery 4:107-114, 1979

19. Ruelle A, Mariotti E, Boccardo M: "True" cystic meningioma. J Neurol Neurosurg Psychiatry 48:716-718, 1985

20. Tali ET, Yuh WT, Nguyen HD, Feng G, Koci TM, Jinkins JR, et al: Cystic acoustic schwannomas: MR characteristics. AJNR Am J Neuroradiol 14:1241-1247, 1993

21. Wilson-Pauwels L, Stewart PA, Akesson EJ, Space SD: Cranial Nerves: Function and Dysfunction, ed 3. Shelton, CT: People's Medical Publishing House, 2010, pp 143-162

22. Zhang D, Hu LB, Zhen JW, Zou LG, Feng XY, Wang WX, et al: MRI findings of intracranial cystic meningiomas. Clin Radiol 64:792-800, 2009

\section{Author Contributions}

Conception and design: Herde, WT Couldwell, Osborn. Acquisition of data: Herde, Hoang, G Couldwell, Osborn. Analysis and interpretation of data: Herde, Hoang, Tran, Osborn. Drafting the article: Herde. Critically revising the article: Herde, Hoang, Tran, WT Couldwell, Osborn. Reviewed submitted version of manuscript: Herde. Approved the final version of the manuscript on behalf of all authors: Herde. Statistical analysis: Herde.

\section{Correspondence}

Ryan Herde, 30 North 1900 East, \#1A071, Salt Lake City, UT 84132-2140. email: ryanherde@gmail.com. 